\title{
Cucurbit[8]uril-stabilized charge transfer complexes with diquat driven by pH: a SERS study $\dagger$
}

\author{
María Lorena Roldán,* Santiago Sanchez-Cortes, José Vicente García-Ramos and \\ Concepción Domingo*
}

Received 7th November 2011, Accepted 24th January 2012

DOI: $10.1039 / \mathbf{c} 2 \mathrm{cp} 23503 \mathrm{j}$

In this work, we have studied the $\mathrm{pH}$-dependence of the formation of DQCB[8] complexes by surface-enhanced Raman scattering (SERS) spectroscopy. The SERS spectra suggest that at acidic $\mathrm{pH} \mathrm{CB}[8]$ can form a binary complex with the dication $\mathrm{DQ}^{+2}$ while at higher $\mathrm{pH}$ ternary complexes with the radical cation dimer $\left(\mathrm{DQ}^{+} \bullet\right)_{2}$ and the radical cation-dication dimer $\left(\mathrm{DQ}^{+} \cdot \mathrm{DQ}^{+2}\right)$ are formed. The $\mathrm{pH}$-enhanced diquat (DQ) dimerization inside the cucurbit[8]uril cavity has not been reported until now. In addition, this study provides very valuable information regarding the use of $\mathrm{CB}[8]$ functionalized silver nanoparticles as SERS substrate for sensing applications.

\section{Introduction}

Cucurbit $[n]$ uril $(\mathrm{CB}[n], n=5-8,10)$ hosts are macrocycles characterized by a hydrophobic cavity surrounded by two polar carbonyl portals. ${ }^{1}$ Due to their unusual binding properties they play a prominent role in the design of new supramolecular architectures oriented to the development of molecular devices. The strategy commonly consists of building pseudorotaxanes to design molecular necklaces, switches, shuttles and other molecular machines, also incorporating guest molecules. ${ }^{2}$ In recent years, $\mathrm{CBs}$ and their complexes have been widely investigated because of their wide range of applications, ${ }^{3}$ from chemical sensing and catalysis ${ }^{4}$ to drug delivery. ${ }^{5}$ In all cases, it is of vital importance to control the recognition process through an external stimulus, either chemical ( $\mathrm{pH}$, reductants), photochemical or electrochemical.

Diquat (DQ) is a bipyridinium dicationic herbicide belonging to the viologens family (Fig. 1), which can be rapidly and reversibly reduced to the radical cation $\left(\mathrm{DQ}^{+} \bullet\right.$ ) and subsequently to the neutral molecule $\left(\mathrm{DQ}^{0}\right)$ in aqueous solution. ${ }^{6}$ Since this molecule is a good electron acceptor, it is often linked to supramolecular systems conferring them the ability to form highly stable charge-transfer (CT) complexes with a variety of $\pi$-electron donors. In particular, the viologen inclusion complexes with CBs have attracted much attention since they can be potentially used as molecular switches. ${ }^{2}$ In comparison with its lower size homologues, $\mathrm{CB}[8]$ (Fig. 1) has the additional property of binding two aromatic molecules due to its voluminous cavity,

Instituto de Estructura de la Materia, CSIC, Serrano 121,

28006 Madrid, Spain.E-mail: lorena@iem.cfmac.csic.es,

cdomingo@iem.cfmac.csic.es; Fax: + 34 915645557;

Tel: +34915616800

$\dagger$ Electronic supplementary information (ESI) available. See DOI: $10.1039 / \mathrm{c} 2 \mathrm{cp} 23503 \mathrm{j}$ which makes possible the formation of homo- $(2: 1)$ and hetero$(1: 1: 1)$ ternary complexes stabilized by charge-transfer (CT) interactions. ${ }^{1,2}$ The host-guest complex formation between DQ and $\mathrm{CB}[8]$ at neutral $\mathrm{pH}$ was investigated through spectroscopic techniques ( ${ }^{1} \mathrm{H}$ NMR, UV-vis, and fluorescence), X-ray and cyclic voltammetry. ${ }^{7}$ Their results indicated that when DQ is present as a dication a $1: 1$ inclusion complex of $\mathrm{DQ}^{+2 \bullet} \mathrm{CB}[8]$ is formed. However, when the electrochemically obtained radical cation arises, a binary complex of $\mathrm{DQ}^{+} . \mathrm{CB}[8]$ is selectively formed in preference to the former due to the higher binding affinity shown by the latter.

Although it was earlier observed that some viologen UV-visible spectra are $\mathrm{pH}$-dependent, ${ }^{8}$ little attention has been paid to the $\mathrm{pH}$ response of neither DQ nor its supramolecular complexes with $\mathrm{CB}[8]$. In this work, we have studied the formation of DQCB[8] complexes under the influence of a chemical stimulus such as $\mathrm{pH}$, through SERS spectroscopy. SERS spectroscopy has proved to be a powerful tool to provide useful information regarding not only the adsorption mechanism on the metal surface but also the host-guest binding mode. ${ }^{9}$ This is because changes in the vibrational spectra are correlated with the structural changes occurring in the studied molecules as a consequence of the complex formation and their interaction with the surface. Taking advantage of our previous experience on SERS studies on $\mathrm{DQ}^{10}$ we have investigated the effect of the solid-liquid interface nearby the silver colloidal metal nanoparticles (NPs) on the DQCB[8] complex formation. A laser excitation wavelength of $532 \mathrm{~nm}$ and $\mathrm{Ag}$ colloid were employed.

In order to provide more detailed information about the complex, we have first studied the $\mathrm{CB}[8]$ adsorption on Ag NPs as a function of $\mathrm{pH}$, which is of great importance considering their application as a metal surface functionalizing agent in chemosensing. Only one report dealing with SERS of $\mathrm{CB}[n]$ 

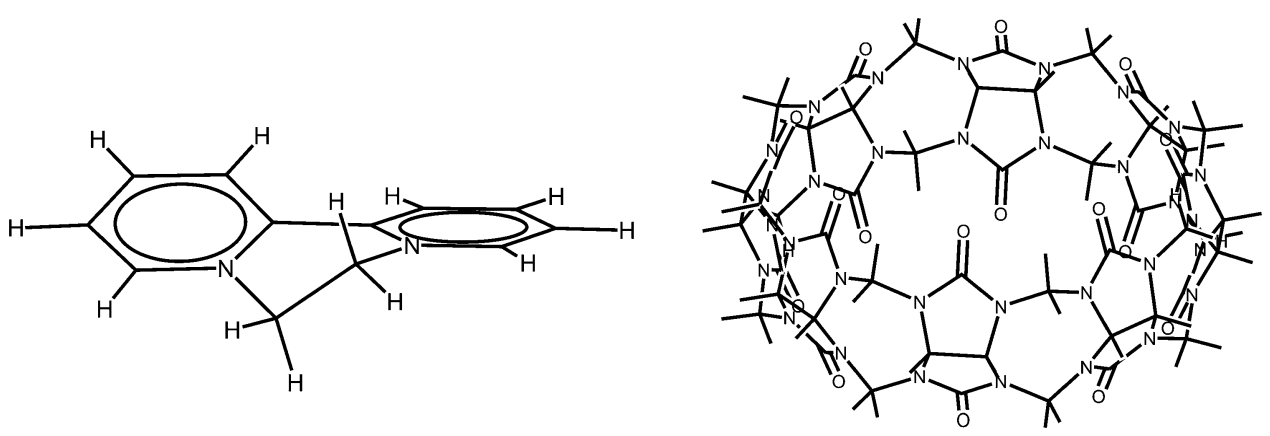

Fig. 1 Chemical structures of the diquat (DQ) guest and cucurbit[8]uril (CB[8]) host macrocycle.

(on a commercial solid SERS substrate) has been reported until now. ${ }^{11}$ Afterwards, we investigated the influence of $\mathrm{pH}$ on DQ adsorption, as the herbicide itself shows a relatively high affinity toward the metal surface. Finally, we have focused on DQCB[8] complex formation and its adsorption on $\mathrm{Ag}$ as a function of $\mathrm{pH}$. Additionally, we have followed the complexes formation in aqueous solution by UV-visible spectroscopy.

\section{Experimental section}

\subsection{Materials}

Diquat dibromide and hydroxylamine hydrochloride (employed for silver colloid fabrication) were purchased from Aldrich with analytical purity. Cucurbit[8]uril (CB[8]) was also supplied by Aldrich with $c a .20 \%$ of water content and acids of crystallization, which was taken into account when preparing the stock solutions. Silver nitrate and potassium nitrate were supplied by Merck with analytical purity. All the aqueous solutions were prepared using Milli-Q water. $\mathrm{CB}[8]$ stock solutions were prepared at a $10^{-4} \mathrm{M}$ concentration gently heating at $30{ }^{\circ} \mathrm{C}$ under agitation. Stock solutions of DQ were prepared with a final concentration of $10^{-2} \mathrm{M}$. These solutions were then diluted to obtain the desired concentrations.

\subsection{Raman, SERS and UV-visible measurements}

SERS spectra were recorded using a Confocal Raman Microscope Renishaw Invia equipped with a Leica microscope and an electrically refrigerated CCD camera. The laser excitation line used was $532 \mathrm{~nm}$ (Nd:YAG laser) and the power in the sample was $0.5 \mathrm{~mW}$. The spectra were obtained as an average of 3 scans of $10 \mathrm{~s}$ each with a spectral resolution of $2 \mathrm{~cm}^{-1}$ and geometry of $180^{\circ}$. CB[8] and DQ Raman spectra in the solid state were recorded on a microconfiguration with 10 scans of $10 \mathrm{~s}$ each with the same resolution. The absorption spectra of aqueous solutions of DQ and DQCB[8] complex were recorded on a UV-vis-NIR Shimadzu 3600 spectrophotometer. Aqueous solutions were placed on a $1 \times 1 \mathrm{~cm}$ path length quartz cuvette and Milli-Q water was employed for calibration.

\subsection{Sample preparation}

Silver NPs were prepared by reduction of silver nitrate with hydroxylamine hydrochloride at room temperature. ${ }^{12}$ For SERS measurements, the silver colloids were first activated with an aliquot of potassium nitrate solution $0.5 \mathrm{M}$ up to a final concentration of $2 \times 10^{-2} \mathrm{M}$. Then, $10 \mu \mathrm{L}$ of $\mathrm{CB}[8]$ and
$10 \mu \mathrm{L}$ of DQ at the suitable concentration were added to $1 \mathrm{~mL}$ of the nitrate-aggregated colloid to obtain the SERS spectra of the host-guest complex. For measurements at different $\mathrm{pH}$ values, $\mathrm{NaOH} 0.5 \mathrm{M}$ or $\mathrm{HNO}_{3} 0.5 \mathrm{M}$ were used for adjusting $\mathrm{pH}$ before the aggregating procedure.

UV-visible characterization (Fig. S1 of ESI $\dagger$ ) of the surface plasmon resonance (SPR) of Ag-colloid at the three $\mathrm{pH}$ values 2,7 and 11 shows a $\lambda_{\mathrm{SPR}}$ around $405-407 \mathrm{~nm}$, according to our previous studies. ${ }^{13}$ The $\lambda_{\text {SPR }}$ of the Ag NPs functionalized by $\mathrm{CB}[8]$ shows a second broad band at $602 \mathrm{~nm}$ for $\mathrm{pH}=2,612 \mathrm{~nm}$ for $\mathrm{pH}=7$ and $650 \mathrm{~nm}$ for $\mathrm{pH}=11$ in the absorption spectra due to the formation of NPs aggregates, as was expected. This band could be originated by the presence of longitudinal aggregates and shifts about $50 \mathrm{~nm}$ to red when $\mathrm{pH}$ decreases proving that different aggregation mechanisms are involved. The guest addition also produces a plasmon resonance red shift with respect to the functionalized $\mathrm{CB}[8] / \mathrm{Ag}$ NPs. TEM micrographs of silver NPs together with silver NPs covered by $\mathrm{CB}[8]$ and $\mathrm{DQCB}[8]$ are also included in ESI. $\dagger$

\subsection{Theoretical vibrational frequencies}

DFT calculations were performed using Gaussian $03^{14}$ package at the B3LYP/6-31G* level of theory for $\mathrm{CB}[8]$. The molecular structure was modelled with $D_{8 \mathrm{~h}}$ symmetry and the optimized parameters were subsequently used to calculate the harmonic force field. Observed bands on the Raman and SERS spectra of $\mathrm{CB}[8]$ along with their assignment are given in Table 1. Additionally, SERS bands for DQ and DQCB[8] complexes are listed in Table S1 of ESI† and Table 2, respectively.

\section{Results and discussion}

\subsection{Raman and SERS spectra of $\mathrm{CB}[8]$}

The poor solubility of $\mathrm{CB}[8]^{15}$ in water prevents its study in aqueous solution by Raman spectroscopy, which sensitivity does not allow us to detect trace amounts. Therefore, the Raman spectrum of an aqueous solution of $\mathrm{CB}$ [8] in the solubility limit $\left(10^{-4} \mathrm{M}\right)$ gives no signal at all, as can be seen in Fig. 2. The Raman spectrum of the solid CB[8] along with its SERS spectra at $\mathrm{pH}=2,7$ and 11 are also included in Fig. 2. Four bands of the spectra of the solid at $1758 \mathrm{~cm}^{-1}$, $1380 \mathrm{~cm}^{-1}, 1228 \mathrm{~cm}^{-1}$ and $656 \mathrm{~cm}^{-1}$ show a strong intensity decrease in the SERS spectra. This fact indicates that, according to the surface selection rules, ${ }^{16,17} \mathrm{CB}[8]$ is adsorbed onto the metal surface by its $\mathrm{C}=\mathrm{O}$ portals with a perpendicular orientation since 
Table 1 Experimental and calculated Raman and SERS $\left(\lambda_{\text {exc }}=532 \mathrm{~nm}\right)$ bands $\left(\mathrm{cm}^{-1}\right)$ for the $\mathrm{CB}[8]$ host and their assignment

\begin{tabular}{|c|c|c|c|c|c|}
\hline \multicolumn{4}{|c|}{$\underline{\text { Experimental }}^{a}$} & \multicolumn{2}{|l|}{ Calculated } \\
\hline \multirow[b]{2}{*}{ Raman solid } & \multicolumn{3}{|l|}{$\underline{\text { SERS }}$} & \multirow[b]{2}{*}{ B3LYP/6-31G* } & \multirow[b]{2}{*}{ Assignment ${ }^{b}$} \\
\hline & $\mathrm{pH}=2$ & $\mathrm{pH}=7$ & $\mathrm{pH}=11$ & & \\
\hline \multicolumn{4}{|l|}{$3000 \mathrm{~s}$} & 3003 & $\nu_{\text {as }}\left(\mathrm{CH}_{2}\right)$ \\
\hline \multicolumn{4}{|l|}{2962 vs } & 2925 & $\nu_{\mathrm{as}}(\mathrm{CH})$ \\
\hline 2941 vs & 2940 vs & 2941 vs & 2942 vs & 2911 & $\nu_{\mathrm{s}}\left(\mathrm{CH}_{2}\right)$ \\
\hline \multicolumn{4}{|r|}{$2910 \mathrm{sh}$} & 2986 & $\nu_{\mathrm{s}}(\mathrm{CH})$ \\
\hline \multicolumn{4}{|l|}{$1758 \mathrm{~s}$} & 1711 & $\nu_{\mathrm{s}}(\mathrm{C}=\mathrm{O})$ \\
\hline \multicolumn{4}{|l|}{$1734 \mathrm{~s}$} & 1690 & $\nu_{\mathrm{as}}(\mathrm{C}=\mathrm{O})$ \\
\hline \multirow[t]{2}{*}{$1426 \mathrm{~s}$} & $1427 \mathrm{~s}$ & $1427 \mathrm{~s}$ & $1427 \mathrm{~s}$ & 1427 & $\operatorname{sciss}\left(\mathrm{CH}_{2}\right)$ \\
\hline & $1404 \mathrm{sh}$ & $1403 \mathrm{sh}$ & $1405 \mathrm{sh}$ & 1386 & $\omega\left(\mathrm{CH}_{2}\right)+\delta(\mathrm{CH})$ \\
\hline \multirow[t]{2}{*}{$1380 \mathrm{~s}$} & $1380 \mathrm{w}$ & $1380 \mathrm{w}$ & $1382 \mathrm{w}$ & 1362 & $\delta\left(\mathrm{CH}_{2}\right)+\gamma(\mathrm{CH})$ \\
\hline & $1320 \mathrm{~m}$ & $1323 \mathrm{~m}$ & $1322 \mathrm{~m}$ & 1329 & $\nu(\mathrm{C}-\mathrm{N})+\nu(\mathrm{C}-\mathrm{C})+\delta(\mathrm{CH})$ \\
\hline $1284 \mathrm{~m}$ & $1282 \mathrm{~m}$ & $1283 \mathrm{~m}$ & $1283 \mathrm{~m}$ & 1280 & $\nu_{\mathrm{s}}(\mathrm{C}-\mathrm{N})+\delta\left(\mathrm{CH}_{2}\right)$ \\
\hline \multicolumn{2}{|l|}{$1228 \mathrm{~m}$} & $1235 \mathrm{vw}$ & $1228 \mathrm{vw}$ & 1234 & $\nu(\mathrm{C}-\mathrm{N})+\rho\left(\mathrm{CH}_{2}\right)+\gamma(\mathrm{CH})$ \\
\hline \multirow{3}{*}{$\begin{array}{l}1190 \mathrm{~m} \\
1138 \mathrm{w}\end{array}$} & $1191 \mathrm{~m}$ & $1193 \mathrm{~m}$ & $1193 \mathrm{~m}$ & 1203 & $\nu(\mathrm{C}-\mathrm{N})+\delta(\mathrm{CH})$ \\
\hline & $1136 \mathrm{vw}$ & $1136 \mathrm{vw}$ & $1143 \mathrm{vw}$ & 1157 & $\nu(\mathrm{HC}-\mathrm{CH})+\delta(\mathrm{CH})$ \\
\hline & & & $1113 \mathrm{vw}$ & 1127 & $\nu(\mathrm{C}-\mathrm{N})+t_{\mathrm{w}}\left(\mathrm{CH}_{2}\right)$ \\
\hline \multirow[t]{2}{*}{$1045 \mathrm{~m}$} & $1044 \mathrm{~m}$ & $1044 \mathrm{~m}$ & $1044 \mathrm{~m}$ & 1082 & $\nu(\mathrm{C}-\mathrm{N})+\rho\left(\mathrm{CH}_{2}\right)+\gamma(\mathrm{CH})$ \\
\hline & 1012 vw & $1013 \mathrm{vw}$ & $1016 \mathrm{vw}$ & 994 & $\nu(\mathrm{HC}-\mathrm{CH})+\delta\left(\mathrm{CH}_{2}\right)$ \\
\hline \multirow[t]{2}{*}{$976 \mathrm{w}$} & $984 \mathrm{vw}$ & 997 vw & & 984 & $\rho\left(\mathrm{CH}_{2}\right)+\nu(\mathrm{C}-\mathrm{N})$ \\
\hline & & & $978 \mathrm{vw}$ & 961 & $\nu(\mathrm{HC}-\mathrm{CH})+\delta(\mathrm{CH})+\tau(\mathrm{HC}-\mathrm{CH})$ \\
\hline \multirow{5}{*}{$\begin{array}{l}906 \mathrm{~m} \\
835 \mathrm{vs} \\
753 \mathrm{~m} \\
656 \mathrm{~m}\end{array}$} & $905 \mathrm{~m}$ & $907 \mathrm{~m}$ & $905 \mathrm{~m}$ & 910 & $\rho\left(\mathrm{CH}_{2}\right)$ \\
\hline & $833 \mathrm{~s}$ & $835 \mathrm{~s}$ & $833 \mathrm{~s}$ & 819 & $\gamma \mathbf{R}_{5}$ \\
\hline & $751 \mathrm{~m}$ & $751 \mathrm{~m}$ & $751 \mathrm{~m}$ & 754 & $\gamma \mathbf{R}_{5}$ \\
\hline & & & & 652 & $\delta_{\text {ring }}+\delta(\mathrm{C}=\mathrm{O})$ \\
\hline & & $476 \mathrm{sh}$ & & 440 & $\delta_{\text {ring }}$ \\
\hline \multirow{4}{*}{$\begin{array}{l}440 \mathrm{vs} \\
370 \mathrm{w} \\
338 \mathrm{w} \\
278 \mathrm{w}\end{array}$} & $441 \mathrm{~s}$ & $441 \mathrm{~s}$ & $441 \mathrm{~s}$ & 423 & $\delta_{\text {ring }}$ \\
\hline & & $373 \mathrm{vw}$ & $371 \mathrm{vw}$ & 373 & $\gamma \mathbf{R}_{8}$ \\
\hline & $338 \mathrm{vw}$ & $333 \mathrm{vw}$ & $334 \mathrm{vw}$ & 333 & $\gamma \mathbf{R}_{8}$ \\
\hline & & & & 282 & $\gamma \mathbf{R}_{8}$ \\
\hline \multicolumn{6}{|c|}{$\begin{array}{l}{ }^{a} \text { vs: very strong; s: strong; m: medium; w: weak, vw: very weak; sh: shoulder. }{ }^{b} \nu \text {, stretching; } \delta \text {, in plane deformation; } \gamma, \text { out of plane deformation; } \\
\text { sciss; scissoring; } \rho \text {, rocking; } t_{\mathrm{w}} \text {, twisting; } \omega \text { : wagging; } \tau \text {, torsion; } \mathrm{R}_{5} \text { : five-membered ring; } \mathrm{R}_{8}: \text { eight-membered ring; s: symmetric, a: antisymmetric. } \\
\text { Frequencies were scaled by a factor of } 0.9613 \text { and } 1.0007 \text { for high and low frequency values, respectively. }{ }^{19}\end{array}$} \\
\hline
\end{tabular}

bands at $1758 \mathrm{~cm}^{-1}$ and $656 \mathrm{~cm}^{-1}$ are related to the stretching and deformation modes of the carbonyl portal groups and bands at $1380 \mathrm{~cm}^{-1}$ and $1228 \mathrm{~cm}^{-1}$ are attributed to $\nu(\mathrm{C}-\mathrm{H})$ and $\nu(\mathbf{C}-\mathbf{N})$ vibrations parallel to the $\mathrm{Ag}$ surface. These results are in agreement with those previously reported. ${ }^{11}$ The proposed assignment of observed Raman and SERS bands is given in Table 1, based on our theoretical calculations at the B3LYP/6$31 \mathrm{G}^{*}$ level of theory. SERS spectra at different $\mathrm{pH}$ values show that a $\mathrm{pH}$ increase results in slight shifts of some bands of the spectra. The close similarity of the Raman of the solid sample and SERS spectra of colloidal suspension is a consequence of the high rigidity of the macrocycle ring, which does not seem to undergo significant structural changes upon adsorption on the metal surface. The band shifts observed in acidic media can be associated with a certain protonation of the macrocycle portals given that the $\mathrm{p} K_{\mathrm{a}}$ of the related $\mathrm{CB}[6]$ was reported to be $3.02 .^{18}$ Likewise, slight changes at alkaline media in comparison with the solid, such as a band at $1193 \mathrm{~cm}^{-1}$ attributed to $\nu(\mathrm{C}-\mathrm{N})+$ $\delta(\mathrm{CH})$, can be related to the inclusion in the cavity of $\mathrm{Na}^{+}$ions.

\subsection{Raman, SERS and electronic spectra of DQ}

The Raman and SERS spectra of DQ at different $\mathrm{pH}$ values are included in Fig. 3. The observed bands in the SERS spectra of DQ at different $\mathrm{pH}$ values are listed in Table S1 of ESI. $\dagger$ The interaction mechanism of DQ with a silver colloidal surface was previously well established by our group. ${ }^{10}$
According to such study, the remarkable change in the spectral profile resulting from DQ absorption on Ag NPs is due to the ionic pair formation with $\mathrm{Br}^{-}$ions attached to the surface. These bromide ions came from stock solutions of DQ since the dication is present as a dibromide salt. The interaction is so strong that the DQ spectra and, therefore the molecular structure closely resembles the radical cation $\mathrm{DQ}^{+} \bullet$. In the present study, the most relevant changes in the spectral profile were found under alkaline conditions. The SERS spectrum at $\mathrm{pH}=11$ shows a noticeable intensity enhancement of some bands in the spectral region of the marker bands associated with the electronic delocalization within rings, such as $1631 \mathrm{~cm}^{-1}, 1611 \mathrm{~cm}^{-1}$ and $1546 \mathrm{~cm}^{-1}$, and those bands related to the aromatic rings planarity, such as $1318 \mathrm{~cm}^{-1}$ and $1291 \mathrm{~cm}^{-1}$. A similar behaviour was earlier observed as a result of shortening the laser excitation wavelength and was attributed to other redox species, apart from the dicationic one, which can be arranged on multilayers. ${ }^{10}$ Additionally, the UV-visible spectra of a $10^{-4} \mathrm{M}$ DQ solution in the absence of a $\mathrm{CB}[8]$ solution were measured at different $\mathrm{pH}$ values. The characteristic absorption band for DQ at $308 \mathrm{~nm}$ undergoes a decrease of the absorption intensity between $\mathrm{pH}=7$ and 12, 30 minutes after the host and guest were in contact (see Fig. S2 of ESI $\dagger$ ). The monitoring of the same DQ solution at $\mathrm{pH}=10$ at repeated time intervals during 12 hours (Fig. S2 of ESI $\dagger$ ) also shows a sequential intensity decrease of $\lambda_{\max }$ for higher contact time. 
Table 2 Experimental SERS $\left(\lambda_{\text {exc }}=532 \mathrm{~nm}\right)$ bands $\left(\mathrm{cm}^{-1}\right)$ observed for DQCB[8] host-guest complexes and their proposed assignment

\begin{tabular}{|c|c|c|c|c|}
\hline SERS $^{a}$ & SERRS & SERRS & & \\
\hline \multirow[t]{3}{*}{$\mathrm{pH}=2$} & $\mathrm{pH}=7$ & $\mathrm{pH}=11$ & Principal contribution & Assignment $^{b}$ \\
\hline & & $3203 \mathrm{vw}$ & $\mathrm{G}$ & $\nu(\mathrm{CH})$ \\
\hline & & $3170 \mathrm{vw}$ & G & $\nu(\mathrm{CH})$ \\
\hline 2939 vs & 2933 vs & $2932 \mathrm{w}$ & $\mathrm{H}$ & $\nu_{\mathrm{s}}\left(\mathrm{CH}_{2}\right)$ \\
\hline \multirow[t]{2}{*}{$2909 \mathrm{sh}$} & $2904 \mathrm{sh}$ & $2908 \mathrm{sh}$ & $\mathrm{H}$ & $\nu_{\mathrm{s}}(\mathrm{CH})$ \\
\hline & $1647 \mathrm{~m}$ & $1646 \mathrm{~m}$ & G & $\nu_{\text {ring }} 8 \mathrm{a}+\delta\left(\mathrm{CH}_{2}\right)$ \\
\hline $1616 \mathrm{~s}$ & $1614 \mathrm{~s}$ & $1616 \mathrm{~m}$ & G & $\nu_{\text {ring }} 8 \mathrm{a}+\delta\left(\mathrm{CH}_{2}\right)$ \\
\hline \multirow[t]{2}{*}{$1583 \mathrm{~s}$} & $1583 \mathrm{~s}$ & $1583 \mathrm{~m}$ & G & $\nu_{\text {ring }}+\nu(\mathrm{C}=\mathrm{N})+\delta\left(\mathrm{CH}_{2}\right)$ \\
\hline & $1560 \mathrm{~s}$ & $1560 \mathrm{vs}$ & $\mathrm{G}$ & $\nu_{\text {ring }}+\nu(\mathrm{C}=\mathrm{N})+\delta\left(\mathrm{CH}_{2}\right)$ \\
\hline \multirow[t]{2}{*}{$1531 \mathrm{~m}$} & $1531 \mathrm{~m}$ & $1533 \mathrm{sh}$ & G & $\nu_{\text {ring }}+\delta(\mathrm{CH})+\delta\left(\mathrm{CH}_{2}\right)$ \\
\hline & $1519 \mathrm{~m}$ & $1519 \mathrm{~m}$ & $\mathrm{G}$ & $\nu_{\text {ring }}+\delta(\mathrm{CH})+\delta\left(\mathrm{CH}_{2}\right)$ \\
\hline $1458 \mathrm{vw}$ & $1480 \mathrm{w}$ & $1480 \mathrm{~m}$ & G & $\delta\left(\mathrm{CH}_{2}\right)$ \\
\hline \multirow[t]{2}{*}{$1428 \mathrm{~s}$} & $1428 \mathrm{~m}$ & & $\mathrm{H}$ & $\operatorname{sciss}\left(\mathrm{CH}_{2}\right)$ \\
\hline & & $1434 \mathrm{~m}$ & $\mathrm{G}$ & $\delta\left(\mathrm{CH}_{2}\right)+\delta(\mathrm{CH})$ \\
\hline $1405 \mathrm{sh}$ & & & $\mathrm{H}$ & $\omega\left(\mathrm{CH}_{2}\right)+\delta(\mathrm{CH})$ \\
\hline \multirow[t]{3}{*}{$1383 \mathrm{~m}$} & $1387 \mathrm{w}$ & & $\mathrm{H}$ & $\delta\left(\mathrm{CH}_{2}\right)+\gamma(\mathrm{CH})$ \\
\hline & & $1384 \mathrm{~m}$ & $\mathrm{G}$ & $\nu_{\text {ring }}+\delta(\mathrm{CH})+t_{\mathrm{w}}\left(\mathrm{CH}_{2}\right)$ \\
\hline & $1377 \mathrm{~m}$ & $1353 \mathrm{~m}$ & G & $\nu(\mathrm{C}-\mathrm{C}) \mathrm{ir}$ \\
\hline $1321 \mathrm{~s}$ & $1321 \mathrm{vs}$ & $1321 \mathrm{~s}$ & $\mathrm{H} / \mathrm{G}$ & $\nu(\mathrm{C}-\mathrm{N})+\nu(\mathrm{C}-\mathrm{C})+\delta(\mathrm{CH}) ; \nu(\mathrm{C}-\mathrm{C}) \mathrm{ir}$ \\
\hline \multirow[t]{3}{*}{$1286 \mathrm{~m}$} & $1282 \mathrm{~m}$ & & $\mathrm{H} / \mathrm{G}$ & $\nu_{\mathrm{s}}(\mathrm{C}-\mathrm{N})+\delta\left(\mathrm{CH}_{2}\right) ; \nu_{\text {ring }}+\delta(\mathrm{CH})+t_{\mathrm{w}}\left(\mathrm{CH}_{2}\right)$ \\
\hline & & $1261 \mathrm{~m}$ & G & $\nu_{\text {ring }}+\delta(\mathrm{CH})+t_{\mathrm{w}}\left(\mathrm{CH}_{2}\right)$ \\
\hline & $1235 \mathrm{~m}$ & $1235 \mathrm{~m}$ & $\mathrm{G}$ & $\omega\left(\mathrm{CH}_{2}\right)$ \\
\hline $1193 \mathrm{~s}$ & $1193 \mathrm{~m}$ & & $\mathrm{H} / \mathrm{G}$ & $\delta(\mathrm{C}-\mathrm{H})+\nu(\mathrm{C}-\mathrm{N}) ; \nu\left(\mathrm{H}_{2} \mathrm{C}-\mathrm{N}\right)+\delta(\mathrm{CH})$ \\
\hline \multirow[t]{3}{*}{$1180 \mathrm{vw}$} & $1174 \mathrm{sh}$ & $1175 \mathrm{~m}$ & $\mathrm{G}$ & $\nu_{\text {ring }}+\delta(\mathrm{CH})$ \\
\hline & & $1165 \mathrm{sh}$ & G & $\nu_{\text {ring }}+\delta(\mathrm{CH})$ \\
\hline & $1148 \mathrm{sh}$ & $1154 \mathrm{sh}$ & G & $\nu_{\text {ring }}+\delta(\mathrm{CH})$ \\
\hline $1077 \mathrm{sh}$ & $1079 \mathrm{sh}$ & & $\mathrm{G}$ & $\delta_{\text {ring }}+\delta(\mathrm{CH})$ \\
\hline $1070 \mathrm{~m}$ & $1069 \mathrm{~m}$ & $1067 \mathrm{w}$ & G & $\delta_{\text {ring }}+\delta(\mathrm{CH})$ \\
\hline $1044 \mathrm{~m}$ & $1042 \mathrm{~m}$ & $1042 \mathrm{w}$ & $\mathrm{H}$ & $\nu(\mathrm{C}-\mathrm{N})+\rho\left(\mathrm{CH}_{2}\right)+\gamma(\mathrm{CH})$ \\
\hline $1011 \mathrm{w}$ & & $1014 \mathrm{vw}$ & $\mathrm{H}$ & $\nu(\mathrm{HC}-\mathrm{CH})+\delta\left(\mathrm{CH}_{2}\right)$ \\
\hline $998 \mathrm{w}$ & $1002 \mathrm{w}$ & $985 \mathrm{vw}$ & $\mathrm{H} / \mathrm{G}$ & $\rho\left(\mathrm{CH}_{2}\right)+\nu(\mathrm{C}-\mathrm{N}) ; \nu\left(\mathrm{H}_{2} \mathrm{C}-\mathrm{CH}_{2}\right)+\gamma(\mathrm{CH})$ \\
\hline $906 \mathrm{~m}$ & $907 \mathrm{~m}$ & $906 \mathrm{w}$ & $\mathrm{H}$ & $\rho\left(\mathrm{CH}_{2}\right)$ \\
\hline $835 \mathrm{~s}$ & $835 \mathrm{~s}$ & $833 \mathrm{w}$ & $\mathrm{H}$ & $\gamma \mathbf{R}_{5}$ \\
\hline $818 \mathrm{sh}$ & & $820 \mathrm{sh}$ & $\mathrm{H}$ & $\gamma \mathbf{R}_{5}$ \\
\hline \multirow[t]{2}{*}{$804 \mathrm{w}$} & $807 \mathrm{sh}$ & $808 \mathrm{w}$ & $\mathrm{H} / \mathrm{G}$ & $\delta_{\text {ring }}+\gamma(\mathrm{CH}) ; \delta_{\text {ring }}+\gamma(\mathrm{CH})$ \\
\hline & & $777 \mathrm{w}$ & $\mathrm{G}$ & $\delta_{\text {ring }}$ \\
\hline $751 \mathrm{~m}$ & $751 \mathrm{~m}$ & $747 \mathrm{w}$ & $\mathrm{H}$ & $\gamma \mathbf{R}_{5}$ \\
\hline \multirow[t]{4}{*}{$736 \mathrm{~m}$} & $736 \mathrm{~m}$ & $732 \mathrm{w}$ & G & $\delta_{\text {ring }}$ \\
\hline & & $702 \mathrm{w}$ & $\mathrm{G}$ & $\tau_{\text {ring }}+\gamma(\mathrm{CH})$ \\
\hline & & $648 \mathrm{vw}$ & $\mathrm{H}$ & $\delta_{\text {ring }}+\delta(\mathrm{C}=\mathrm{O})$ \\
\hline & & $614 \mathrm{vw}$ & G & $\delta_{\text {ring }}+\tau\left(\mathrm{H}_{2} \mathrm{C}-\mathrm{CH}_{2}\right)$ \\
\hline $552 \mathrm{w}$ & $552 \mathrm{~m}$ & $554 \mathrm{vw}$ & $\mathrm{G}$ & $\delta_{\text {ring }}+\gamma(\mathrm{CH})$ \\
\hline \multirow[t]{2}{*}{$539 \mathrm{w}$} & $540 \mathrm{sh}$ & $545 \mathrm{w}$ & $\mathrm{G}$ & $\delta_{\text {ring }}+\gamma(\mathrm{CH})$ \\
\hline & & $484 \mathrm{w}$ & $\mathrm{G}$ & $\tau(\mathrm{C}-\mathrm{C})_{\mathrm{ir}}$ \\
\hline $456 \mathrm{vw}$ & $455 \mathrm{sh}$ & $462 \mathrm{sh}$ & $\mathrm{H}$ & $\delta_{\text {ring }}$ \\
\hline \multirow[t]{3}{*}{$441 \mathrm{~s}$} & $441 \mathrm{~s}$ & $441 \mathrm{w}$ & $\mathrm{H}$ & $\delta_{\text {ring }}$ \\
\hline & & $424 \mathrm{sh}$ & $\mathrm{H}$ & $\delta_{\text {ring }}$ \\
\hline & & $411 \mathrm{w}$ & $\mathrm{G}$ & $\tau_{\text {ring }}$ \\
\hline \multirow[t]{3}{*}{$373 \mathrm{w}$} & $371 \mathrm{vw}$ & $376 \mathrm{w}$ & $\mathrm{H}$ & $\gamma \mathbf{R}_{8}$ \\
\hline & & $363 \mathrm{sh}$ & $\mathrm{H}$ & $\gamma \mathbf{R}_{8}$ \\
\hline & & $309 \mathrm{vw}$ & G & $\tau_{\text {ring }}+\tau\left(\mathrm{H}_{2} \mathrm{C}-\mathrm{CH}_{2}\right)$ \\
\hline $276 \mathrm{w}$ & $277 \mathrm{w}$ & $278 \mathrm{w}$ & $\mathrm{H}$ & $\gamma \mathbf{R}_{8}$ \\
\hline
\end{tabular}

${ }^{a}$ vs: very strong; s: strong; m: medium; w: weak, vw: very weak; sh: shoulder. ${ }^{b} \nu$, stretching; $\delta$, in plane deformation; $\gamma$, out of plane deformation; sciss; scissoring; $\rho$, rocking; $t_{\mathrm{w}}$, twisting; $\omega$, wagging; $\tau$, torsion; ir: inter-ring; $\mathrm{R}_{5}$ : five-membered ring; $\mathrm{R}_{8}$ : eight-membered ring; s: symmetric, a: antisymmetric. H: host; G: guest.

\subsection{Raman, SERS and electronic spectra of DQCB[8]}

The formation of a host-guest complex between the herbicide and the macrocycle $\mathrm{CB}[8]$ in aqueous solution at acidic and alkaline $\mathrm{pH}$ was confirmed by isosbestic points observed with increasing host concentration (Fig. S3 of ESI $\dagger$ ). Also, the stoichiometries of the formed complexes under both conditions were investigated by means of Job's plot analysis (Fig. S4 of ESI $\dagger$ ). Interestingly, these data reveal that at acidic $\mathrm{pH}$ a $1: 1$ complex can be formed whereas ternary $2: 1$ complexes can be observed at alkaline $\mathrm{pH}$. Therefore, the stoichiometry of DQCB[8] complexes in aqueous solution depends on the selected $\mathrm{pH}$. Taking this into account, DQCB[8] complex adsorption on the metal surface was also studied by varying $\mathrm{pH}$, as is displayed in Fig. 4. A proposed assignment of the observed bands in the SERS spectra of DQCB[8] at different $\mathrm{pH}$ values is given in Table 2. Two different spectrochemical behaviours were observed for the host-guest complex according to $\mathrm{pH}$ ranges. Under acidic conditions $(\mathrm{pH}=2-5)$, the spectral region of DQ marker bands in the SERS spectra of the complex 

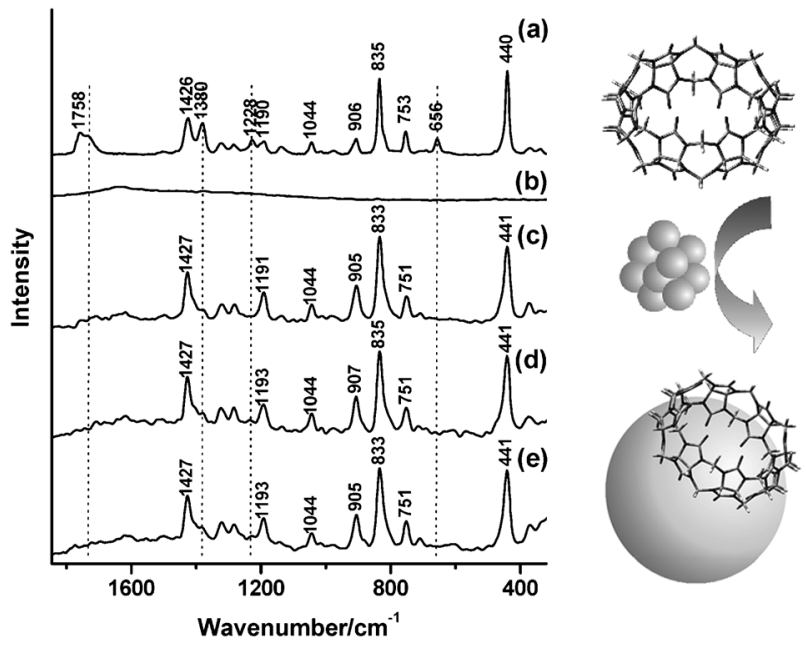

Fig. 2 Raman spectra of $\mathrm{CB}[8]$ (a) solid and (b) $10^{-4} \mathrm{M}$ aqueous solution; and SERS spectra of $10^{-6} \mathrm{M}$ solution of $\mathrm{CB}[8]$ on Ag colloid at (c) $\mathrm{pH}=2$, (d) $\mathrm{pH}=7$ and (e) $\mathrm{pH}=11 . \lambda_{\text {exc }}=532 \mathrm{~nm}$.
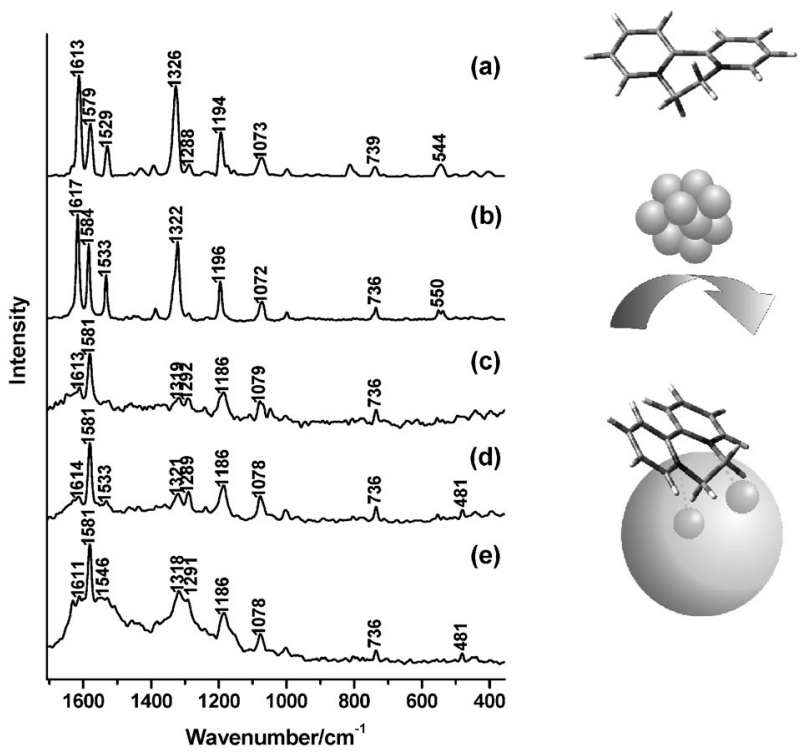

Fig. 3 Raman spectra of DQ (a) solid and (b) $0.5 \mathrm{M}$ aqueous solution; and SERS spectra of $10^{-5} \mathrm{M}$ solution of DQ on Ag colloid at (c) $\mathrm{pH}=2$, (d) $\mathrm{pH}=7$ and (e) $\mathrm{pH}=11 . \lambda_{\mathrm{exc}}=532 \mathrm{~nm}$.

resembles the Raman spectra of DQ solid and $0.5 \mathrm{M}$ solution. This is proved by bands located at $1616 \mathrm{~cm}^{-1}, 1583 \mathrm{~cm}^{-1}, 1531 \mathrm{~cm}^{-1}$ and $1321 \mathrm{~cm}^{-1}$, as is shown in Fig. 5. Moreover, since the SERS spectra of DQ adsorbed on the metal surface strongly differs from the SERS spectrum for the complex at $\mathrm{pH}=2$, it can be deduced that DQ is encapsulated within $\mathrm{CB}[8]$ avoiding their direct interaction with the Ag NPs. Bands appearing below $1300 \mathrm{~cm}^{-1}$ are principally due to the macrocycle molecular vibrations (see Fig. 2). The analysis of the SERS spectra reveals that vibrational modes which involve the aromatic ring and the aliphatic chain of $1077 \mathrm{~cm}^{-1}\left(1079 \mathrm{~cm}^{-1}\right)$ and $998 \mathrm{~cm}^{-1}\left(1002 \mathrm{~cm}^{-1}\right)$ bands corresponding to $\delta_{\text {ring }}+\beta(\mathrm{CH})$, and $\nu\left(\mathrm{H}_{2} \mathrm{C}-\mathrm{CH}_{2}\right)$ are shifted, in comparison with that of DQ in the absence of $\mathrm{CB}[8]$. Slight shifts in $\mathrm{CB}$ [8] spectra are in agreement with results from an X-ray study ${ }^{7}$ which shows that the guest can be included in

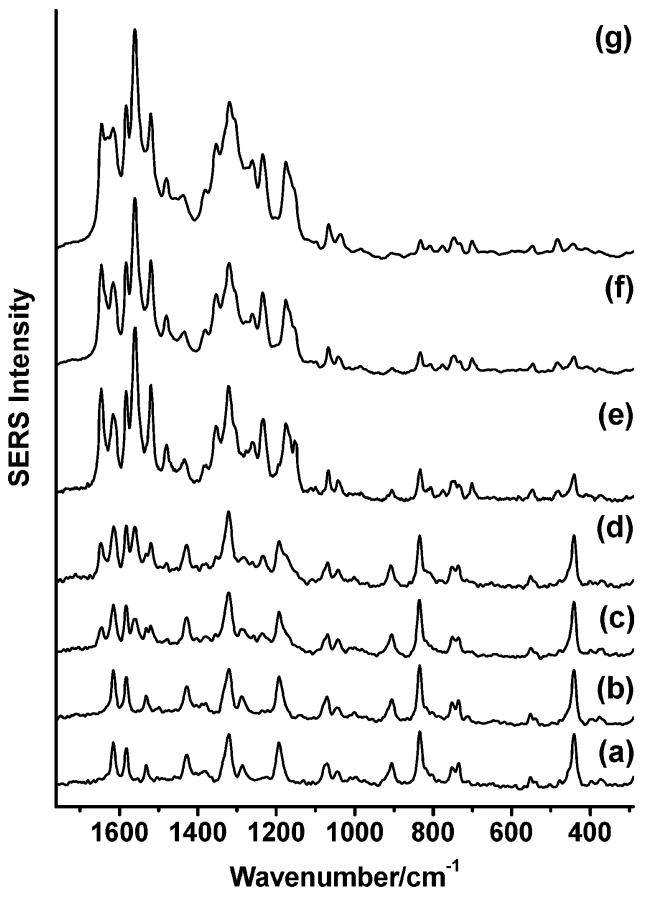

Fig. 4 SERS and SERRS spectra of DQCB[8] solution of $10^{-5}$ $\mathrm{M} / 10^{-6} \mathrm{M}$ concentration on $\mathrm{Ag}$ colloid at (a) $\mathrm{pH}=2$, (b) $\mathrm{pH}=5$, (c) $\mathrm{pH}=6$, (d) $\mathrm{pH}=7$, (e) $\mathrm{pH}=9$, (f) $\mathrm{pH}=11$ and (g) $\mathrm{pH}=12$. Spectra (e)- $(\mathrm{g})$ were scaled to fit into the graph. $\lambda_{\text {exc }}=532 \mathrm{~nm}$.
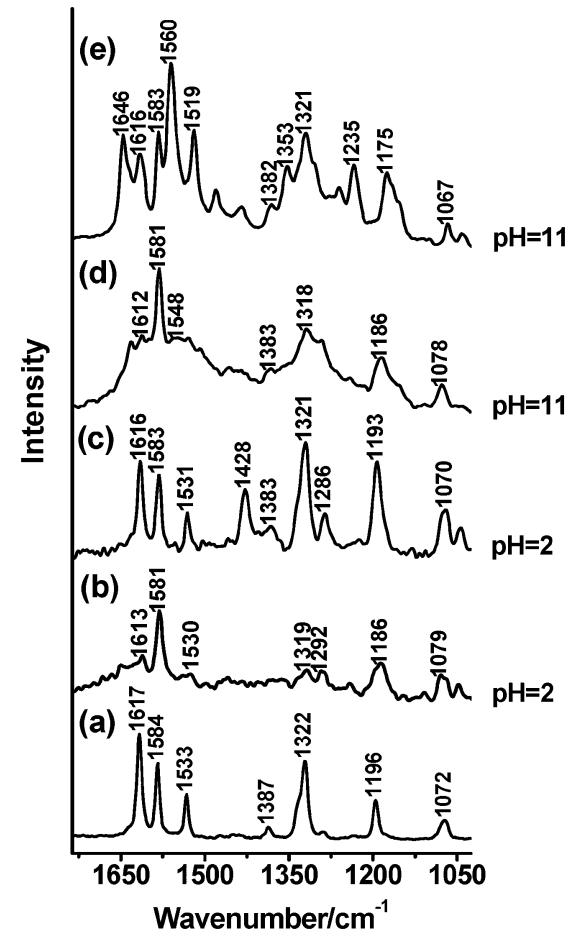

Fig. 5 Raman spectra of (a) $0.5 \mathrm{M}$ aqueous solution of DQ and SERS spectra on Ag colloid of (b) DQ $10^{-5} \mathrm{M}$ at $\mathrm{pH}=2$, (c) DQCB[8] $10^{-5}$ $\mathrm{M} / 10^{-6} \mathrm{M}$ at $\mathrm{pH}=2$, (d) DQ $10^{-5} \mathrm{M}$ at $\mathrm{pH}=11$ and (e) DQCB[8] $10^{-5}$ $\mathrm{M} / 10^{-6} \mathrm{M}$ at $\mathrm{pH}=11$ in the region of the marker bands. $\lambda_{\mathrm{exc}}=532 \mathrm{~nm}$.

$\mathrm{CB}[8]$ without any significant distortion of the macrocycle. On the other hand, for $\mathrm{pH} \geq 6$ the spectral profile changes drastically. For a better understanding of the processes 
occurring at alkaline $\mathrm{pH}$ the absorption spectra of a $10^{-4} \mathrm{M}$ solution of DQ in the presence of $10^{-5} \mathrm{M} \mathrm{CB}[8]$ solution were measured by varying $\mathrm{pH}$, as can be shown in Fig. 6 . The data show that while $\lambda_{\max }$ at $308 \mathrm{~nm}$ decreases for all the $\mathrm{pH}$ range measured, two new bands located at $347 \mathrm{~nm}$ and $495 \mathrm{~nm}$ arise at $\mathrm{pH}=9$, whose intensities increase with raising $\mathrm{pH}$. This fact is accompanied by a concomitant color change of the colorless solution to red. Moreover, these bands undergo a blue shift from $349 \mathrm{~nm}$ to $347 \mathrm{~nm}$ and a noticeable red shift from $488 \mathrm{~nm}$ to $492 \mathrm{~nm}$ as the concentration of $\mathrm{CB}$ [8] host is increased (Fig. S3 of ESI $\dagger$ ). These new bands were previously observed for the reduction of the dication with several reductants (cysteine, dithionite, mercaptoethanol, etc.) at alkaline $\mathrm{pH}^{20,22}$ and were assigned to the radical cation species. ${ }^{22}$ The temporal evolution of the same concentration of DQCB[8] solution at $\mathrm{pH}=10$ is shown in Fig. 6. Here, the two characteristic bands for the radical cation also appear and reach the maximum absorption 80 minutes after the reactants were in contact. Then, these bands diminish until two new bands can be clearly distinguished at $280 \mathrm{~nm}$ and $372 \mathrm{~nm}$. The yellow color of the solution at this point probably can be associated with the appearance of the totally reduced form of DQ. ${ }^{20-23}$ Surprisingly, it seems that redox species of DQ can be formed under alkaline conditions. In the absence of $\mathrm{CB}[8]$, higher concentrations of DQ and higher $\mathrm{pH}$ conditions $(\mathrm{pH}=11$ and 12$)$ are required for the process to occur (see discussion on Fig. S5 of ESI $\dagger$ ). Conversely, $\mathrm{CB}[8]$ addition could prompt the reaction in such a way that CT bands can be observed at $\mathrm{pH}$ two units lower than without $\mathrm{CB}[8]$.

Furthermore, under alkaline conditions a resonant effect between the laser excitation wavelength at $532 \mathrm{~nm}$ and the absorption band observed at $495 \mathrm{~nm}$ in solution leads to SERRS (surface-enhanced resonance Raman scattering) spectra for DQCB[8] (see Fig. 6). In Fig. 3 remarkable SERS enhancements and band shifts occur in the whole spectra, particularly in the marker band region. Bands related to the ring $\pi$-delocalization at $1616 \mathrm{~cm}^{-1}$ and $1583 \mathrm{~cm}^{-1}$ are greatly enhanced as well as new strong bands at $1646 \mathrm{~cm}^{-1}, 1560 \mathrm{~cm}^{-1}$ and $1519 \mathrm{~cm}^{-1}$ experience an intensity increase as $\mathrm{pH}$ increases. Also, new bands around $1321 \mathrm{~cm}^{-1}$ can be observed. Variations in the marker bands region at alkaline $\mathrm{pH}$ can be observed in detail in Fig. 5. Taking in mind the results obtained from the $\mathrm{UV}$-visible spectra of the complex at alkaline $\mathrm{pH}$, we propose that those pronounced changes observed in the SERRS spectra are due to the dimer formation of $\left(\mathrm{DQ}^{+} \bullet\right)_{2}$ and $\left(\mathrm{DQ}^{+} \cdot \mathrm{DQ}^{+2}\right)$ like species within the $\mathrm{CB}[8]$ cavity. These face-to-face dimers are stabilized by CT interactions inside the cavity overcoming the steric repulsion effect from the lateral aliphatic chain and giving rise to the intense red color of the solution. This is an important finding regarding the application of $\mathrm{CB}[8]$ as a
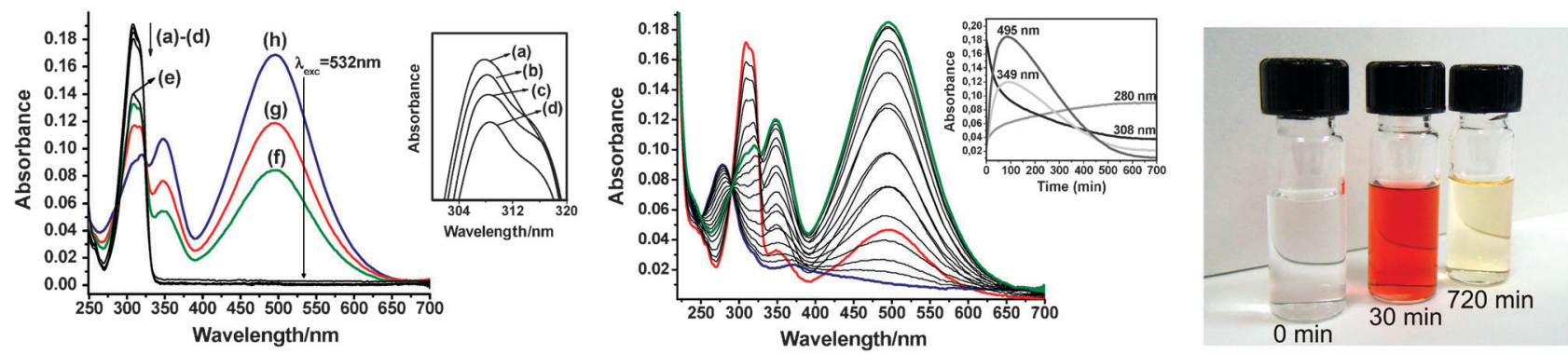

Fig. 6 (left) UV-visible absorption spectra of $10^{-5} \mathrm{M} / 10^{-6} \mathrm{M}$ aqueous solution of DQCB[8] at (a) $\mathrm{pH}=2$, (b) $\mathrm{pH}=3$, (c) $\mathrm{pH}=5$, (d) $\mathrm{pH}=7$, (e) $\mathrm{pH}=8$, (f) $\mathrm{pH}=10,(\mathrm{~g}) \mathrm{pH}=11$ and (h) $\mathrm{pH}=12$ after 30 minutes. Inset: absorption decrease from $\mathrm{pH}=2$ to $\mathrm{pH}=7$. (middle) Temporal evolution of the same solution of DQCB[8] at $\mathrm{pH}=10$ from $T=0$ to $T=24 \mathrm{~h}$. Inset: absorption variation of bands at $280 \mathrm{~nm}, 308 \mathrm{~nm}, 349 \mathrm{~nm}$ and $495 \mathrm{~nm}$. (right) Color change of a $10^{-4} \mathrm{M} / 10^{-5} \mathrm{M}$ DQCB[8] solution with time.

$\mathrm{DQ}^{+2} \underset{\mathrm{H}+}{\stackrel{\mathrm{OH}^{-}}{\rightleftarrows}} \mathrm{DQ}^{+\cdot} \underset{\mathrm{H}^{+}}{\stackrel{\mathrm{OH}^{-}}{\rightleftarrows}} \mathrm{DQ}^{\mathbf{0}}$
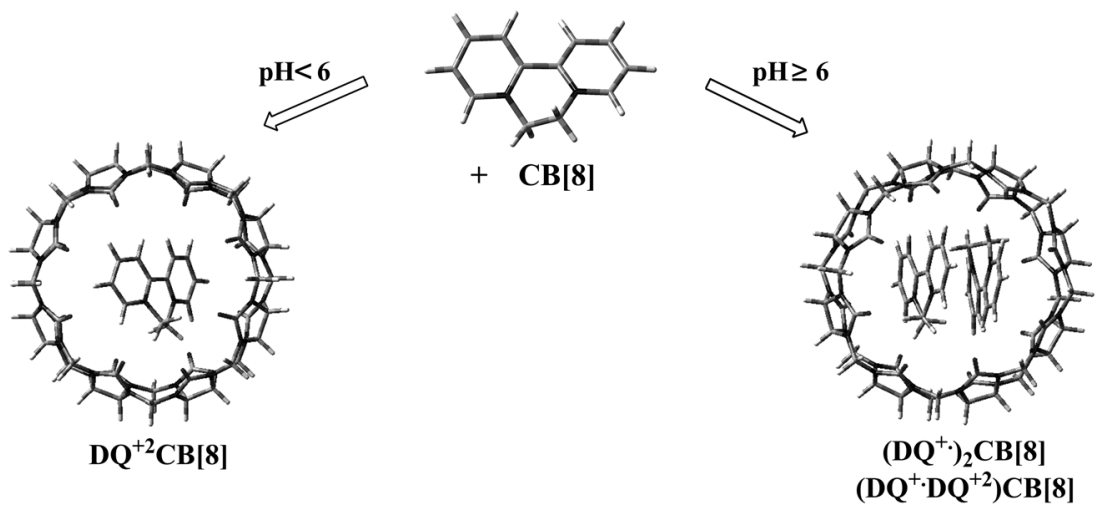

Fig. 7 Scheme of inclusion complexation of DQ inside CB[8]. 
chemical sensor for detecting hazardous pesticides and opens the possibility to be applied in soil remediation. The use of $\mathrm{CB}[8]$ to remediate polluted alkaline soils should have the advantage of selectively removing two molecules instead of one. Also, the color change provides a rapid detection method of DQ in soils reducing the detection limit that previously was achieved with a chemical reductant. ${ }^{21}$ The complexation process between DQ and $\mathrm{CB}[8]$ is represented in Fig. 7.

In order to get a better insight on the interaction mechanism of the DQ guest with the $\mathrm{CB}[8]$ receptor molecule, two different approaches were followed. First, an aliquot of the $10^{-6} \mathrm{M} \mathrm{CB}[8]$ solution was added to the silver NPs previously aggregated with $\mathrm{KNO}_{3} 0.5 \mathrm{M}$. Subsequently, an aliquot of the $10^{-5} \mathrm{M}$ DQ solution was added to the mixture. Second, an aliquot of the $10^{-5} \mathrm{M} / 10^{-6} \mathrm{M}$ DQCB[8] complex solution was added to the nitrate aggregated silver NPs. The resulting SERS spectra (Fig. S6 of ESI $\dagger$ ) show that regardless of the $\mathrm{pH}$ value, the spectral profile does not show significant changes. Due to the fact that $\mathrm{CB}[n]$ are bifunctional agents it is expected that not only they can selectively bind a guest molecule but also they have the capability to act as a bridging ligand producing the so-called hot spots. Therefore, from the similarity among SERS spectra it can be deduced that DQ is certainly able to be included within the internal cavity of $\mathrm{CB}[8]$ molecules which link silver NPs, in the same way as it does in aqueous solution.

Also, it is interesting to note that the spectral changes associated with the $2: 1$ complex formation become evident at $\mathrm{pH}=6$ in the SERS spectra immediately after adding the host and the guest to the colloid, whereas for the UV-visible spectra they can be observed at $\mathrm{pH}=9$ and required a certain contact time. This fact can be explained by the great sensitivity of the SERS technique, which allows detecting only those species that are selectively bound to the surface, independently of the bulk solution. Furthermore, the metallic superficial effect seems to favor the formation of $\mathrm{DQ}^{+} \bullet$, as was deduced from the adsorption study of DQ on Ag NPs. ${ }^{10}$

\section{Conclusions}

The formation of DQCB[8] complexes is highly dependent on $\mathrm{pH}$. We have shown that an increase in $\mathrm{pH}$ induces the cation radical formation and also, the addition of $\mathrm{CB}[8]$ promotes their dimerization within the cavity due to the spatial restriction imposed by the host. The $\mathrm{CB}[8] / \mathrm{Ag}$ NPs were successfully employed as a chemical sensor based on surface enhanced spectroscopy for detecting DQ herbicide, providing very useful structural information. The approach followed in this work could be applied as a general technique for sensing viologen herbicides and also for analyzing $\mathrm{CB}[n]$ complexes. Further studies exploring the influence of the excitation wavelength and the effect of the guest concentration on the formation of these complexes are currently in progress.

\section{Acknowledgements}

This work has been supported by the Spanish Ministerio de Ciencia e Innovación (FIS2010-1405) and Comunidad de Madrid (S2009/TIC-1476). M. L. R. also acknowledges a MAEC-AECID post-doctoral fellowship from the Ministerio de Asuntos Exteriores.

\section{References}

1 J. Lagona, P. Murkhopadhyay, S. Chakrabarti and L. Isaacs, Angew. Chem., Int. Ed., 2005, 44, 4844; L. Isaacs, Chem. Commun., $2009,619$.

2 Y. H. Yo, E. Kim, I. Hwang and K. Kim, Chem. Commun., 2007, 1305.

3 G. Parvari, O. Reany and E. Keinan, Isr. J. Chem., 2011, 51, 646.

4 C. Pemberton, N. Baroah, D. K. Srivatsava and J. Sivaguru, Chem. Commun., 2010, 46, 225.

5 S. Walker, R. Oun, F. J. McInnes and N. J. Wheate, Isr. J. Chem., 2011, 51, 616.

6 P. Monk, The Viologens Physicochemical Properties, Synthesis and Applications of the Salts of 4,4'-Bipyridine, Wiley, New York, 1998.

7 Y. Ling, J. Mague and A. E. Kaifer, Chem.-Eur. J., 2007, 13, 7908.

8 V. Sindelar, S. Silvi and A. E. Kaifer, Chem. Commun., 2006, 2185.

9 E. H. Witlicki, S. W. Hansen, M. Christensen, T. S. Hansen, S. D. Nygaard, J. O. Jeppesen, E. W. Wong, L. Jensen and A. H. Flood, J. Phys. Chem. A, 2009, 113, 9450 and references therein.

10 M. R. López-Ramírez, L. Guerrini, J. V. García-Ramos and S. Sanchez-Cortes, Vib. Spectrosc., 2008, 48, 58 and references therein.

11 S. Mahajan, T.-C. Lee, F. Biedermann, J. T. Hugall, J. J. Baumberg and O. A. Scherman, Phys. Chem. Chem. Phys., 2010, 12, 10429.

12 N. Leopold and B. Lendl, J. Phys. Chem. B, 2003, 107, 5723.

13 M. V. Cañamares, J. V. Garcia-Ramos, J. D. Gomez-Varga, C. Domingo and S. Sanchez-Cortes, Langmuir, 2005, 21, 8546.

14 M. J. Frisch, G. W. Trucks, H. B. Schlegel, G. E. Scuseria, M. A. Robb, J. R. Cheeseman, G. Scalmani, V. Barone, B. Mennucci, G. A. Petersson, H. Nakatsuji, M. Caricato, X. Li, H. P. Hratchian, A. F. Izmaylov, J. Bloino, G. Zheng, J. L. Sonnenberg, M. Hada, M. Ehara, K. Toyota, R. Fukuda, J. Hasegawa, M. Ishida, T. Nakajima, Y. Honda, O. Kitao, H. Nakai, T. Vreven, J. J. A. Montgomery, J. E. Peralta, F. Ogliaro, M. Bearpark, J. J. Heyd, E. Brothers, K. N. Kudin, V. N. Staroverov, R. Kobayashi, J. Normand, K. Raghavachari, A. Rendell, J. C. Burant, S. S. Iyengar, J. Tomasi, M. Cossi, N. Rega, N. J. Millam, M. Klene, J. E. Knox, J. B. Cross, V. Bakken, C. Adamo, J. Jaramillo, R. Gomperts, R. E. Stratmann, O. Yazyev, A. J. Austin, R. Cammi, C. Pomelli, J. W. Ochterski, R. L. Martin, K. Morokuma, V. G. Zakrzewski, G. A. Voth, P. Salvador, J. J. Dannenberg, S. Dapprich, A. D. Daniels, Ö. Farkas, J. B. Foresman, J. V. Ortiz, J. Cioslowski and D. J. Fox, Wallingford, CT, 2009.

15 K. Kim, N. Selvapalam, Y. H. Ko, K. M. Park, D. Kim and J. Kim, Chem. Soc. Rev., 2007, 36, 267.

16 J. Gersten and A. J. Nitzan, Chem. Phys., 1980, 73, 3023.

17 J. A. Creighton, The Selection Rules for Surface-Enhanced Raman Spectroscopy, in Spectroscopy of Surfaces, John Wiley \& Sons, New York, 1988.

18 H.-J. Buschmann, E. Cleve and E. Schollmeyer, Inorg. Chim. Acta, 1992, 193, 93.

19 J. P. Merrick, D. Moran and L. Radom, J. Phys. Chem. A, 2007, 111, 11683.

20 K. Minakata, O. Suzuki and M. Asano, Forensic Sci. Int., 1989, 42, 231.

21 K. Minakata, O. Sisuki, T. Kumazawa, M. Asano and N. Harada, Z. Rechtsmed., 1990, 103, 599.

22 A. Sánchez-Palacios and R. Delgado, Appl. Spectrosc., 1994, 48, 926.

23 D. J. Barker, R. P. Cooney and L. A. Summers, J. Raman Spectrosc., 1985, 16, 265. 